Research Paper

\title{
Polymorphic Allele of Human MRC1 Confer Protection against Tuberculosis in a Chinese Population
}

\author{
Xing Zhang ${ }^{1}$, Feng Jiang ${ }^{2}$, Liliang Wei ${ }^{3}$, Fujian Li ${ }^{4}$, Jiyan Liu ${ }^{1,5}$, Chong Wang ${ }^{1}$, Menyuan Zhao ${ }^{1}$, Tingting \\ Jiang ${ }^{1}$, Dandan $\mathrm{Xu}^{1}$, Dapeng Fan ${ }^{4}$, Xiaojun Sun ${ }^{3}$, Ji-Cheng $\mathrm{Li}^{1}{ }^{1,} \bowtie$ \\ 1. Institute of Cell Biology, Zhejiang University, Hangzhou 310058, P.R.China; \\ 2. Dongzhimen Hospital Affiliated to Beijing University of Chinese Medicine, Beijing 100700, P.R. China; \\ 3. The Sixth Hospital of Shaoxing, Shaoxing 312000, P.R. China; \\ 4. Hangzhou Red Cross Hospital, Hangzhou 310003, P.R. China; \\ 5. Department of Cell Biology, Hangzhou Normal University, Hangzhou 310036, P.R. China.
}

Corresponding author: Ji-Cheng Li, Zhejiang University School of Medicine, No. 866, Yuhangtang Road, Hangzhou 310058, China. Tel: +86 571-88208088; Fax: +86 571-88208088. Email: lijichen@zju.edu.cn.

(C) Ivyspring International Publisher. This is an open-access article distributed under the terms of the Creative Commons License (http://creativecommons.org/ licenses/by-nc-nd/3.0/). Reproduction is permitted for personal, noncommercial use, provided that the article is in whole, unmodified, and properly cited.

Received: 2012.01.04; Accepted: 2012.02.16; Published: 2012.02.23

\begin{abstract}
Mannose receptor is a member of the C-type lectin receptor family involved in pathogen molecular-pattern recognition, and plays a critical role in shaping host immune response. Single nucleotide polymorphisms (SNPs) in the $\mathrm{MRCl}$ gene may affect expression levels and differences in the structure and function of proteins in different individuals, thereby affecting individual susceptibility to pulmonary tuberculosis. However, to date, $\mathrm{MRCl}$ polymorphisms associated with susceptibility to pulmonary tuberculosis have not yet been reported. The present study aimed to investigate potential associations of SNPs in the MRCI gene with pulmonary tuberculosis in a Chinese population. Six SNPs (GII86A, GII95A, TI2I2C, $\mathrm{CI} 22$ IG, CI303T and CI323T) in exon 7 of the $M R C I$ gene were genotyped using the PCR and DNA sequencing methods in the pulmonary tuberculosis patients and the healthy controls. Linkage disequilibrium analysis was performed between polymorphic sites. The study found that the allele frequency of GII86A (rs34039386) of the MRCI gene in a Chinese population was higher in the pulmonary tuberculosis group than the healthy control group. There was a significant difference in frequency distribution between the two groups $(P=$ $0.037 ; \mathrm{OR}=0.76 ; 95 \% \mathrm{Cl}, 0.58-0.98)$. Genotypic analysis also indicated that the AG genotypes in a Chinese population were significantly correlated with pulmonary tuberculosis $(P<0.0 \mathrm{I}$; $\mathrm{OR}=0.57 ; 95 \% \mathrm{Cl}, 0.37-0.87)$. After adjustment for age and gender, $\mathrm{GI}$ I $86 \mathrm{~A}$ sites were found to be dominant $(P<0.01$; OR $=0.59 ; 95 \% \mathrm{Cl}, 0.40-0.87)$, over-dominant $(P=0.045 ; \mathrm{OR}=$ $0.69 ; 95 \% \mathrm{Cl}, 0.47-0.99)$ and additive models $(P=0.04 \mathrm{I}$; $\mathrm{OR}=0.76 ; 95 \% \mathrm{Cl}, 0.59-0.99)$ in association with pulmonary tuberculosis. But, no association was found between the other 5 SNPs (GII95A, TI2I2C, CI22IG, Cl303T and CI323T) and tuberculosis $(P>0.05)$. This study is the first to report that genetic variants in the $M R C I$ gene can be associated with pulmonary tuberculosis in a Chinese population, and may reduce the risk of infecting pulmonary tuberculosis. This also provides a new experimental basis to clarify the pathogenesis of pulmonary tuberculosis.
\end{abstract}

Key words: Mannose receptor; MRC1 gene; Tuberculosis; Single-nucleotide polymorphism; Chinese. 


\section{Introduction}

Tuberculosis (TB) is one of the world's most serious public health threats. Over the past several years, China is most profoundly affected by TB. Each year, the new cases of $\mathrm{TB}$ account for $18 \%$ of the world's population [1]. Although about one third of the world's population is thought to be infected with Mycobacterium tuberculosis (MTB), only 5-15\% of people develop clinically active TB during their lifetime [2]. Some evidence suggests that certain genetic factors may be involved in innate immunity and play important roles in susceptibility to TB at the individual level. Genetic studies showed that both genes and environmental factors are associated with the pathogenesis of TB [3, 4]. Therefore, it is important to identify genes that mediate susceptibility to TB.

TB is an infectious disease caused by MTB, which mainly lives on the monocyte/macrophage system. Cellular immunity is involved in resistance to infectious disease caused by MTB. Activated macrophages perceive the invasion of MTB and lead to active and passive immune response, such as, antigen presenting, $\mathrm{T}$ cell activation, $\mathrm{B}$ cell activation, the production of interleukin (IL), interferon (IFN) and transformation growth factor (TGF) [5]. So, monocyte/macrophage system plays a key role in the early identification of MTB and the incidence of pulmonary TB [5]. Pattern recognition receptors (PRRs) are located on the surface of the macrophages and dendritic cells, which belong to the body's natural immune system and are the core of the receptor molecules identifying the pathogen. Many classes of PRRs have been described, including Toll-like receptors (TLR), NOD-like receptors (NLR) and C-type lectin receptors (CLR) [6-8]. Recently, polymorphisms in the TLR [3, 9-18] and NLR [19, 20] genes have been shown to be associated with susceptibility to pulmonary TB. The mannose receptor (MR) belongs to CLR, and the predisposition of $M R C 1$ gene variants to pulmonary TB have not been reported yet.

MR is a member of the CLR family, which plays an important role in innate immunity [21]. MR is predominantly present on alveolar macrophages and dendritic cells and recognizes glycan structures containing mannose, fucose and $\mathrm{N}$-acetylglucoasmine, which are commonly found on the cell walls of pathogenic micro-organism such as mycobacteria, fungus, parasites, and yeast [6, 22, 23]. MR binds to mannose-capped lipoarabinomannans (ManLAM), a cell wall component of MTB [24, 25], loaded to the antigen-presenting cells (APC), and then presented to $\mathrm{T}$ cells which play a role in immune response [26]. MR can also help macrophages to phagocytize MTB [27,
28] and plays an important role in innate immunity $[25,26]$. The $M R C 1$ gene, encoding the human MR, is located on chromosome 10p12 and consist of 30 exons. Several reports have shown that the MRC1 gene is associated with the susceptibility to some diseases, such as asthma, sarcoidosis and leprosy [29-31]. We speculated that the MRC1 gene may be an excellent candidate for susceptibility to TB, and tested for associations between $M R C 1$ polymorphisms and the pulmonary TB in our Chinese case-control analysis.

\section{Materials and Methods}

\section{Patients and Control Subjects}

A total of 222 Chinese subjects with pulmonary TB, aged 18-66 years (mean age $37.5 \pm 8.6$ years) were recruited from the Sixth Hospital of Shaoxing and Hangzhou Red Cross Hospital. The diagnosis of pulmonary TB was made according to established criteria [32], 98 cases were confirmed by the $M$. tuberculosis cultures and 124 cases were diagnosed by chest X-ray and computed tomography (CT) revealing evidence of typical active tuberculosis. A total of 232 healthy controls, aged 20-64 years (mean age 39.6 \pm 9.4 years) were recruited from the Zhejiang Hospital between October 2008 and July 2011 (Table 1).

The early morning, fasting blood samples from the patients and controls were collected in $3.0 \mathrm{~mL}$ EDTA tubes and stored at $-70^{\circ} \mathrm{C}$. For each gene polymorphisms, it was ensured that the final selected samples of TB patients were similar to controls in the ratio of gender, age, presence of TB history of relatives, BCG vaccination and Tuberculin skin test $(>10$ $\mathrm{mm})$. This study was approved by the Ethics Committee of the Faculty of Medicine (Zhejiang University, China), and informed consents were obtained from all subjects before blood sampling.

\section{Genotyping}

We acquired the MRC1 gene sequence by using the NCBI Gene database (http://www.ncbi.nlm. nih.gov/gene) and the Ensemble Genome Browser Database (http:/ / asia.ensembl.org). We also obtained the information of single nucleotide polymorphisms (SNPs) in this gene by using dbSNP database (http://www.ncbi.nlm.nih.gov/snp/), and screened the frequency of SNPs by using HapMap database (http://www.hapmap.org).

Finally, we selected six SNPs in exon 7 of the MRC1 gene, G1186A (rs34039386, Gly396Ser), G1195A (rs71497223, Gly396Ser), T1212C (rs71497224, Ile404Ile), C1221G (rs34284571, Leu407Phe), C1303T (Leu435 Phe) and C1323T (Asn441Asn). 
Table I. Characteristics of healthy controls and TB patients.

\begin{tabular}{|c|c|c|c|}
\hline \multirow[t]{3}{*}{ Characteristics } & \multicolumn{3}{|c|}{ Chinese population $(n=454)$} \\
\hline & Patients & Controls & \\
\hline & $(n=222)$ & $(\mathrm{n}=232)$ & $P$ value \\
\hline \multirow[t]{2}{*}{ Age, years range (mean $\pm \mathrm{SD}$ ) } & $18-66$ & $20-64$ & $0.534^{\mathrm{a}}$ \\
\hline & $(37.5 \pm 8.6)$ & $(39.6 \pm 9.4)$ & \\
\hline Gender ( female: male) & 108:114 & $117: 125$ & --- \\
\hline Sputum culture-proven & $98(44.1 \%)$ & ND & --- \\
\hline Chest X-ray and CT-proven & $124(55.9 \%)$ & ND & --- \\
\hline Pulmonary TB & $222(100 \%)$ & ND & --- \\
\hline Tuberculin skin test (>10 mm), no. (\%) & $188(86.7 \%)$ & ND & --- \\
\hline Presence of TB history of relatives, no. (\%) & $20(9 \%)$ & $29(3.9 \%)$ & $0.231^{\mathrm{b}}$ \\
\hline BCG vaccination, no. (\%) & $113(50.9 \%)$ & $128(55.2 \%)$ & $0.195^{b}$ \\
\hline
\end{tabular}

Data are reported as number with percent in parentheses, unless otherwise stated. TB: tuberculosis; ND: not determined. aDifference be-

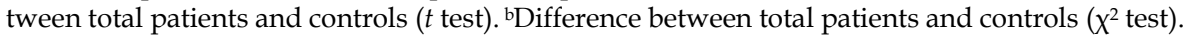

SNPs in the MRC1 gene were analyzed by polymerase chain reaction (PCR) and direct sequencing. Genomic DNAs were extracted from the peripheral blood leukocytes with DNA extraction kit (QIAamp ${ }^{\circledR}$ DNA Blood Min Kit, Germany) according to the manufacturer's instruction.

The PCR primer included forward: TTGAGGCTGCAATGAGACAT and reverse: AGTGTAAGGTAGACTGCTCT. The PCR was performed by denaturing at $95^{\circ} \mathrm{C}$ for $5 \mathrm{~min}$, followed by 35 cycles at $95^{\circ} \mathrm{C}$ for $50 \mathrm{~s}, 63^{\circ} \mathrm{C}$ for $50 \mathrm{~s}$, and $72{ }^{\circ} \mathrm{C}$ for $30 \mathrm{~s}$, and a final extension at $72{ }^{\circ} \mathrm{C}$ for $10 \mathrm{~min}$. The amplified products were purified with PCR cleaning kit (AxyPrep PCR cleaning kit, USA) and then identified by scanning with the ABI 3100 sequencer (Applied Biosystems, Carlsbad, CA, USA).

\section{Statistical Analysis}

The chi-square test was used to compare allele and genotype distribution in the TB patients and control subjects by the two-tailed Fisher exact method with the GraphPad Prism version 5.01 software. The odd ratio (OR) and $95 \%$ confidence interval $(\mathrm{CI})$ were calculated by Miettinen's method. The value of OR is used to estimate the relative risk. If the value of OR is equal to 1 , it indicates that the factor has no effect on the incidence of disease. If the value of OR is greater than 1 , it indicates that the factor is a risk to the incidence of disease. If the value of OR is less than 1 , it indicates that the factor is protective.

Pairwise linkage disequilibrium was calculated with SNPstas (http://bioinfo.iconcologia.net/ SNPstats), which was estimated by calculating pairwise based on $\mathrm{D}^{\prime} \quad\left(\mathrm{D}^{\prime}\right.$ value is the relative size of the LD linkage disequilibrium, which is on behalf of the differences between the expected haplotype frequency and the observed haplotype frequency and scaled in $[-1,1]$ range) and $R$ ( $R$ is the correlation coefficient between alleles) that are on behalf of the degree of linkage disequilibrium between each pair of SNPs [33]. Values of $\mathrm{D}^{\prime}>0.75$ were considered to be strong pairwise linkage disequilibrium and we construct haplotypes between each pair of SNPs. Haplotype frequencies and associations were calculated with expectation-maximization algorithm. Using logistic regression method, we calculated the allele combinations of OR values and 95\% CI referring to the highest frequency of haplotype allele and the additive genetic model. $P$ value was calculated to estimate haplotype association with pulmonary TB.

\section{Results}

The $M R C 1$ gene was amplified and sequenced by PCR in all samples. Six polymorphisms were found in this region. All MRC1 SNPs were in Hardy-Weinberg equilibrium in the control group and the pulmonary TB group $(P>0.05)$ (Table 2). The frequencies of the G/G, A/G and A/A genotypes for the G1186A site in the control group were $0.267,0.517$ and 0.216 , respectively, while, the frequencies of the three genotypes in the pulmonary TB group were $0.383,0.423$ and 0.194 , respectively. The frequency of $\mathrm{A} / \mathrm{G}$ genotype was lower in the pulmonary TB group than the control group and there was a significant difference between the two groups $(P<0.01$; OR $=0.57 ; 95 \% \mathrm{CI}, 0.37$ $0.87)$, but the frequency of $\mathrm{A} / \mathrm{A}$ genotype was not significantly different between the two groups $(P>$ $0.05)$. No significant differences between patients and controls were observed in the genotype distribution of G1195A, T1212C, C1221G, C1303T and C1323T ( $P$ > 
0.05) (Table 3).

The allele frequency of $G$ for the G1186A was higher in the pulmonary TB group than the control group and there was a significant difference between the two groups $(P=0.037$; OR $=0.76 ; 95 \% \mathrm{CI}$,
0.58-0.98) (Table 2). The allele frequencies of G1195A, T1212C, C1221G, C1303T and C1323T were not significantly different between patients and controls $(P>$ 0.05) (Table 2).

Table 2. Distribution of the MRCI SNP allele frequencies in the TB group $(n=222)$ and the control group $(n=232)$ in a Chinese population.

\begin{tabular}{|c|c|c|c|c|c|}
\hline SNP sites & Allele & Controls N(Freq) & Patients N(Freq) & $P$ value & OR $(95 \% \mathrm{CI})$ \\
\hline \multirow[t]{3}{*}{ G1186A } & G & $244(0.526)$ & $264(0.595)$ & 0.037 & 1 \\
\hline & $\mathrm{A}$ & $220(0.474)$ & $180(0.405)$ & & $0.76(0.58-0.98)$ \\
\hline & $\operatorname{HWE}(P)$ & 0.57 & 0.07 & & \\
\hline \multirow[t]{3}{*}{ G1195A } & G & $464(1.000)$ & $441(0.993)$ & 0.076 & 1 \\
\hline & $\mathrm{A}$ & $0(0.000)$ & $3(0.007)$ & & $7.37(0.38-143.1)$ \\
\hline & $\operatorname{HWE}(P)$ & 1.00 & 0.92 & & \\
\hline \multirow[t]{3}{*}{$\mathrm{T} 1212 \mathrm{C}$} & $\mathrm{T}$ & $404(0.871)$ & $376(0.847)$ & 0.302 & 1 \\
\hline & $\mathrm{C}$ & $60(0.129)$ & $68(0.153)$ & & $1.22(0.84-1.77)$ \\
\hline & $\operatorname{HWE}(P)$ & 0.61 & 0.05 & & \\
\hline \multirow[t]{3}{*}{ C1221G } & $\mathrm{C}$ & $464(1.000)$ & $441(0.993)$ & 0.076 & 1 \\
\hline & G & $0(0.000)$ & $3(0.007)$ & & $7.37(0.38-143.1)$ \\
\hline & $\operatorname{HWE}(P)$ & 1.00 & 0.92 & & \\
\hline \multirow[t]{3}{*}{ C1303T } & $\mathrm{C}$ & $462(1.000)$ & $441(0.993)$ & 0.076 & 1 \\
\hline & $\mathrm{T}$ & $0(0.000)$ & $3(0.007)$ & & $7.37(0.38-143.1)$ \\
\hline & $\operatorname{HWE}(P)$ & 1.00 & 0.92 & & \\
\hline \multirow[t]{3}{*}{ C1323T } & $\mathrm{T}$ & $457(0.989)$ & $434(0.977)$ & 0.168 & 1 \\
\hline & $\mathrm{C}$ & $5(0.011)$ & $10(0.023)$ & & $2.11(0.73-6.21)$ \\
\hline & $\operatorname{HWE}(P)$ & 0.87 & 0.73 & & \\
\hline
\end{tabular}

SNP: single nucleotide polymorphism; HWE: Hardy-Weinberg equilibrium; OR: odd ratio; CI: confidence interval; N: number of alleles; Freq: frequency. $P$ value and OR were obtained by Chi-square test. Two-tailed Fisher's exact test was used because of small sample numbers. All of the MRC1 SNPs were in Hardy-Weinberg equilibrium.

Table 3. Distribution of the MRCI SNP genotype frequencies in the TB group $(n=222)$ and the control group $(n=232)$ in a Chinese population.

\begin{tabular}{|c|c|c|c|c|c|}
\hline SNP sites & Genotype & Controls N (Freq) & Patients N (Freq) & $P$ value & OR $(95 \%$ CI) \\
\hline \multirow[t]{3}{*}{ G1186A } & GG & $62(0.267)$ & $85(0.383)$ & & 1 \\
\hline & AG & $120(0.517)$ & $94(0.423)$ & $<0.01$ & $0.57(0.37-0.87)$ \\
\hline & $\mathrm{AA}$ & $50(0.216)$ & $43(0.194)$ & 0.079 & $0.63(0.37-1.06)$ \\
\hline \multirow[t]{3}{*}{ G1195A } & GG & $232(1.000)$ & $219(0.986)$ & & 1 \\
\hline & AG & $0(0.000)$ & $3(0.014)$ & 0.076 & $7.42(0.38-144.5)$ \\
\hline & AA & $0(0.000)$ & $0(0.000)$ & -- & -- \\
\hline \multirow[t]{3}{*}{$\mathrm{T} 1212 \mathrm{C}$} & TT & $175(0.754)$ & $163(0.734)$ & & 1 \\
\hline & CT & $54(0.233)$ & $50(0.225)$ & 0.978 & $0.99(0.64-1.54)$ \\
\hline & $\mathrm{CC}$ & $3(0.013)$ & $9(0.041)$ & 0.068 & $3.22(0.86-12.1)$ \\
\hline \multirow[t]{3}{*}{ C1221G } & $\mathrm{CC}$ & $232(1.000)$ & $219(0.986)$ & & 1 \\
\hline & CG & $0(0.000)$ & $3(0.014)$ & 0.076 & 7.42(0.38-144.5) \\
\hline & GG & $0(0.000)$ & $0(0.000)$ & -- & --- \\
\hline \multirow[t]{3}{*}{ C1303T } & $\mathrm{CC}$ & $232(1.000)$ & $219(0.986)$ & & 1 \\
\hline & CT & $0(0.000)$ & $3(0.014)$ & 0.076 & 7.42(0.38-144.5) \\
\hline & TT & $0(0.000)$ & $0(0.000)$ & -- & --- \\
\hline \multirow[t]{3}{*}{ C1323T } & TT & $226(0.978)$ & $212(0.955)$ & & 1 \\
\hline & $\mathrm{CT}$ & $5(0.022)$ & $10(0.045)$ & 0.164 & $2.13(0.72-6.34)$ \\
\hline & $\mathrm{CC}$ & $0(0.000)$ & $0(0.000)$ & -- & --- \\
\hline
\end{tabular}

SNP: single nucleotide polymorphism; OR: odds ratios; CI: confidence intervals; N: number of alleles; Freq: frequency. P-value and OR were obtained by Chi-square test. Two-tailed Fisher's exact test was used because of small sample numbers. 
We performed logistic repression analysis with all SNPs using a recessive model adjusted for age and sex and observed that G1186A SNP was associated with the pulmonary TB in co-dominant, dominant $(P$ $<0.01$; OR $=0.59 ; 95 \% \mathrm{CI}, 0.40-0.87$ ), over-dominant $(P=0.045 ; \mathrm{OR}=0.69 ; 95 \% \mathrm{CI}, 0.47-0.99)$ and additive model $(P=0.041 ; \mathrm{OR}=0.76 ; 95 \% \mathrm{CI}, 0.59-0.99)$ (Table 4 , Table 5). According to the minimum Akaike information criterion (AIC), this genetic model was the dominant mode. However, the genetic model of other SNPs did not correlate with the pulmonary TB $(P>$ 0.05).

Pairwise LD between the 6 SNPs of the MRC1 gene was calculated for the cases and controls in a Chinese population (Figure 1). We found strong LD
( $\left.\mathrm{D}^{\prime}>0.75, P<0.0001\right)$ between some pairs of markers in the MRC1 gene including G1186A and C1221G, G1186A and C1323T, G1195A and T1212C, G1195A and G1221C, G1195A and C1303T, T1212C and C1221G, T1212C and C1303T, C1221G and C1303T. Therefore, based on logistic-regression analyses, we observed that the haplotype of each SNP pair was associated with pulmonary TB (Table 6). We found that the frequency of the haplotype AGTCCT in the pulmonary TB group was higher than the control group, whereas, the frequency of the haplotype GGTCCT, GGCCCT, GGTCCC in the pulmonary TB group was lower than the control group. All haplotypes with the MRC1 gene polymorphisms showed no significant association with pulmonary TB (Table 6).

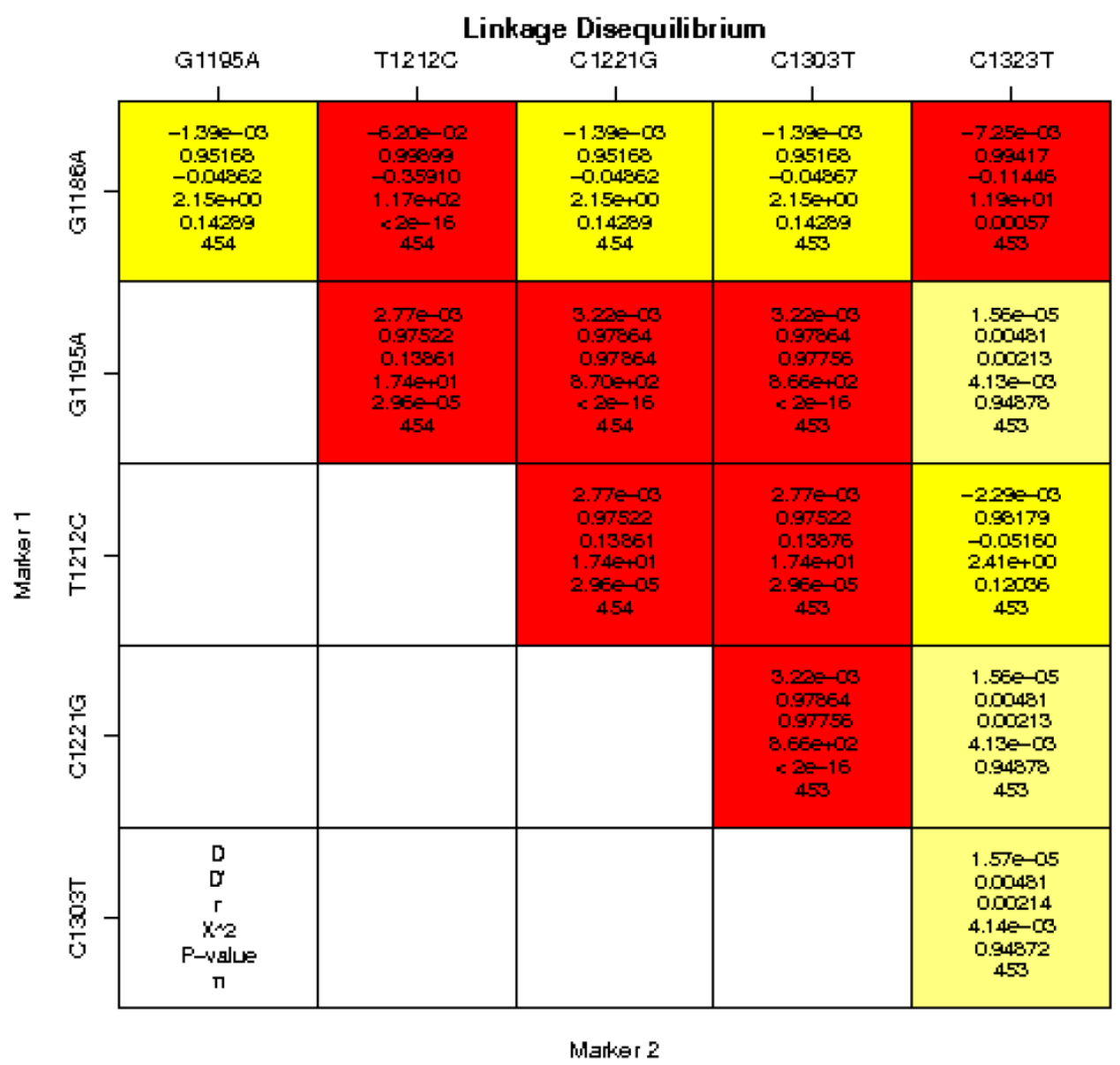

Figure I. Linkage disequilibrium analysis of single-nucleotide polymorphisms (SNPs) in the $M R C I$ gene in a Chinese population. The number at the intersection of each pair of SNPs represents the pairwise $D, D^{\prime}, r^{2}$ and $P$ values between two SNPs. Values of $D^{\prime}>0.75$ were considered to be strong pairwise linkage disequilibrium. 
Table 4. Association of $M R C I$ polymorphisms with TB in a Chinese population with logistic regression.

\begin{tabular}{|c|c|c|c|c|c|c|c|c|}
\hline \multirow[t]{3}{*}{ SNP sites } & \multicolumn{2}{|c|}{ Dominant modela } & \multicolumn{2}{|c|}{ Recessive modela $^{a}$} & \multicolumn{2}{|c|}{ Additive model ${ }^{\mathrm{a}}$} & \multicolumn{2}{|c|}{ Log-additive model ${ }^{a}$} \\
\hline & OR & $P$ & OR & $P$ & OR & $P$ & OR & $P$ \\
\hline & $(95 \% \mathrm{CI})$ & & $(95 \% \mathrm{CI})$ & & $(95 \% \mathrm{CI})$ & & $(95 \% \mathrm{CI})$ & \\
\hline G1186A & $\begin{array}{l}0.58 \\
(0.39-0.87)\end{array}$ & $<0.01$ & $\begin{array}{l}0.88 \\
(0.56-1.39)\end{array}$ & 0.56 & $\begin{array}{l}0.68 \\
(0.47-0.98)\end{array}$ & 0.045 & $\begin{array}{l}0.76 \\
(0.59-0.99)\end{array}$ & 0.041 \\
\hline $\mathrm{T} 1212 \mathrm{C}$ & $\begin{array}{l}1.10 \\
(0.72-1.69)\end{array}$ & 0.62 & $\begin{array}{l}3.21 \\
(0.86-12.02)\end{array}$ & 0.061 & $\begin{array}{l}0.95 \\
(0.61-1.48)\end{array}$ & 0.85 & $\begin{array}{l}1.20 \\
(0.83-1.73)\end{array}$ & 0.31 \\
\hline
\end{tabular}

aAdjusted for age and sex. Freq: frequency; OR: odd ratio; CI: confidence interval.

Table 5. The association of GI I86A with TB in a Chinese population using logistic regression

\begin{tabular}{|c|c|c|c|c|c|c|c|}
\hline Model $^{a}$ & Genotype & Patients & Controls & OR $(95 \% \mathrm{CI})$ & $P$ & AIC & $\mathrm{BIC}$ \\
\hline \multirow[t]{3}{*}{ Codominant } & $\mathrm{G} / \mathrm{G}$ & $85(38.3 \%)$ & $62(26.7 \%)$ & 1.00 & 0.029 & 628.1 & 640.4 \\
\hline & $\mathrm{G} / \mathrm{A}$ & $94(42.3 \%)$ & $120(51.7 \%)$ & $0.57(0.37-0.87)$ & & & \\
\hline & $\mathrm{A} / \mathrm{A}$ & $43(19.4 \%)$ & $50(21.6 \%)$ & $0.63(0.37-1.06)$ & & & \\
\hline \multirow[t]{2}{*}{ Dominant } & $\mathrm{G} / \mathrm{G}$ & $85(38.3 \%)$ & $62(26.7 \%)$ & 1.00 & 0.0084 & 626.2 & 634.4 \\
\hline & G/A-A/A & $137(61.7 \%)$ & $170(73.3 \%)$ & $0.59(0.40-0.87)$ & & & \\
\hline \multirow[t]{2}{*}{ Recessive } & G/G-G/A & $179(80.6 \%)$ & $182(78.5 \%)$ & 1.00 & 0.56 & 632.8 & 641.1 \\
\hline & $\mathrm{A} / \mathrm{A}$ & $43(19.4 \%)$ & $50(21.6 \%)$ & $0.87(0.55-1.38)$ & & & \\
\hline \multirow[t]{2}{*}{ Overdominant } & G/G-A/A & $128(57.7 \%)$ & $112(48.3 \%)$ & 1.00 & 0.045 & 629.1 & 637.4 \\
\hline & $\mathrm{G} / \mathrm{A}$ & $94(42.3 \%)$ & $120(51.7 \%)$ & $0.69(0.47-0.99)$ & & & \\
\hline Log-additive & --- & -- & -- & $0.76(0.59-0.99)$ & 0.041 & 629 & 637.2 \\
\hline
\end{tabular}

aAdjusted for age and sex. OR: odd ratio; 95\% CI: 95\% confidence interval; AIC: Akaike's Information Criterion; BIC: Bayesian Information Criterion.

Table 6. Haplotype frequencies of polymorphisms variants of the $M R C I$ gene in patients with TB $(n=222)$ and healthy controls $(n=232)$ in a Chinese population

\begin{tabular}{|c|c|c|c|c|c|c|c|c|c|c|c|}
\hline \multirow[t]{2}{*}{ Haplotype } & \multicolumn{6}{|c|}{ Allele at marker } & \multirow{2}{*}{$\begin{array}{l}\text { Controls } \\
\text { N(Freq) }\end{array}$} & \multirow{2}{*}{$\begin{array}{l}\text { Patients } \\
\text { N(Freq) }\end{array}$} & \multirow{2}{*}{$\begin{array}{l}\text { Total } \\
\text { N(Freq) }\end{array}$} & \multirow[t]{2}{*}{ OR $(95 \%$ CI $)$} & \multirow[t]{2}{*}{$P$-value } \\
\hline & G1186A & G1195A & $\mathrm{T} 1212 \mathrm{C}$ & C1221G & C1303T & $\mathrm{C} 1323 \mathrm{~T}$ & & & & & \\
\hline 1 & A & G & $\mathrm{T}$ & $\mathrm{C}$ & C & $\mathrm{T}$ & 0.4741 & 0.4054 & 0.4405 & 1.00 & --- \\
\hline 2 & G & G & $\mathrm{T}$ & $\mathrm{C}$ & $\mathrm{C}$ & $\mathrm{T}$ & 0.3857 & 0.4189 & 0.4020 & $1.24(0.93-1.65)$ & 0.13 \\
\hline 3 & G & G & $\mathrm{C}$ & C & C & $\mathrm{T}$ & 0.1293 & 0.1464 & 0.1377 & $1.28(0.87-1.90)$ & 0.21 \\
\hline 4 & G & G & $\mathrm{T}$ & C & C & C & 0.0108 & 0.0225 & 0.0166 & $2.42(0.80-7.30)$ & 0.11 \\
\hline
\end{tabular}

Global haplotype association p-value: 0.063

aAdjusted for age and sex. Freq: frequency of haplotype; OR: odds ratio; CI: confidence interval.

\section{Discussion}

Recent studies have reported that MR plays an important role in innate and adaptive immunity [7]. These receptors activate immune response by extracellular carbohydrate recognition that binds the glycan structures of microbial pathogens, and may play an important role in TB infection [23]. However, polymorphisms in the MRC1 gene, encoding MR, have not been reported to be associated with pulmonary TB. We postulated that MRC1 polymorphisms may be associated with the development of pulmonary TB. Six SNPs in exon 7 of the MRC1 gene were analyzed. The results showed that both the frequency of genotype $(P=0.037$; OR $=0.76 ; 95 \% \mathrm{CI}, 0.58-0.98)$ and allele $(P<0.01 ; \mathrm{OR}=0.57 ; 95 \% \mathrm{CI}, 0.37-0.87)$ for the G1186A (rs34039386) site were significantly different between the pulmonary TB group and the con- 
trol group. The OR values of genotype and allele for G1186A were less than 1, indicating that MRC1 polymorphisms have effects on the development of pulmonary $\mathrm{TB}$, and may reduce the risk of being infected with pulmonary TB.

The G1186A site of MRC1 is non-synonymous mutation that changes Gly to Ser. The mutation of this site may change the function of MR, which may also affect the binding of MR protein to polysaccharide structure on the MTB surface, thus, contributing to the secretion of anti-inflammatory factors. Meanwhile, we also analyzed association between the established haplotype of MRC1 gene and the incidence of pulmonary TB. The results showed that haplotype AGTCCT, GGTCCT, GGCCCT and GGTCCC in the $M R C 1$ gene had no significant association with pulmonary TB $(P>0.05)$. In addition, the other 5 polymorphism sites of MRC1 gene [G1195A (rs71497223, Gly396Ser), T1212C (rs71497224, Ile404Ile), C1221G (rs34284571, Leu407Phe), C1303T (Leu435Phe) and C1323T (Asn441Asn)] also showed no significant association with pulmonary TB $(P>0.05)$, suggesting that these polymorphism sites were not associated with susceptibility to pulmonary TB.

Andrea et al. [29] found that the allele frequency of G1186A site in the exon 7 of $M R C 1$ gene had significant disparity between leprosy per se cases and healthy controls in the Vietnamese population $(P=$ 0.036 , $\mathrm{OR}=0.76 ; 95 \% \mathrm{CI}, 0.60-0.96)$. The OR value was less than 1, and the results showed that this site has significant protective role for leprosy and may reduce the risk of leprosy infection. Similarly, the allele frequency of G1186A site was also found to be significantly different between leprosy per se cases and healthy controls $(P=0.016, \mathrm{OR}=1.34 ; 95 \% \mathrm{CI}$, 1.06-1.70) in the Brazilian population [29]. The OR value was more than 1 , suggesting that this polymorphism is associated with susceptibility to leprosy. Hattori et al. [30] reported that the allele frequency of G1186A site in the exon 7 of $M R C 1$ gene had no significant association with asthma in the Japanese population. We proposed that the individual differences caused by genetic factors, may be the key factor in the difference of disease susceptibility and the gene polymorphisms [4]. In the present study, we analyzed alleles, genotypes and haplotypes, and concluded that the G1186A polymorphism of MRC1 gene was associated with $\mathrm{TB}$, and may have a protective function.

\section{Acknowledgements}

This work was supported by grants from Zhejiang Province Special Sci-Tech Projects (No.2009C03011-3), National Natural Science Foundation of China (No.81072724), and National Special
Sci-Tech Projects

No.2008ZX10005-010).

(No.2012ZX10005001-006;

\section{Conflict of Interests}

The authors have declared that no conflict of interest exists.

\section{References}

1. Vashishtha VM. WHO Global Tuberculosis Control Report 2009: Tuberculosis elimination is a distant dream. Indian Pediatr. 2009; 46: 401-2.

2. Rosman MD O-EA. Clinical presentation and treatment of tuberculosis. In: Fishman AP, eds. Fishman's Pulmonary Diseases and Disorders . New York, USA: McGraw-Hill. 1998: 2483-502.

3. Xue $\mathrm{Y}$, Jin $\mathrm{L}, \mathrm{Li} \mathrm{AZ}$, et al. Microsatellite polymorphisms in intron 2 of the toll-like receptor 2 gene and their association with susceptibility to pulmonary tuberculosis in Han Chinese. Clin Chem Lab Med. 2010; 48: 785-9.

4. Delgado JC, Baena A, Thim S, et al. Ethnic-specific genetic associations with pulmonary tuberculosis. J Infect Dis. 2002; 186: 1463-8.

5. Tsolaki AG. Innate immune recognition in tuberculosis infection. Adv Exp Med Biol. 2009; 653: 185-97.

6. Brown GD. Dectin-1: a signalling non-TLR pattern-recognition receptor. Nat Rev Immunol. 2006; 6: 33-43.

7. Jo EK. Mycobacterial interaction with innate receptors: TLRs, C-type lectins, and NLRs. Curr Opin Infect Dis. 2008; 21: 279-86.

8. Hill AV. Aspects of genetic susceptibility to human infectious diseases. Annu Rev Genet. 2006; 40: 469-86.

9. Ma X, Liu Y, Gowen BB, et al. Full-exon resequencing reveals toll-like receptor variants contribute to human susceptibility to tuberculosis disease. PLoS One. 2007; 2: e1318.

10. Jin L, Zhu XF, Zhong JP, et al. The Arg753Gln Polymorphism of the Human Toil-like Receptor 2 Gene and Its Association with Tuberculosis Disease in Zhejiang Han Population Chinese. Chinese Journal of Cell Biology. 2007; 29: 229-31.

11. Newport MJ, Allen A, Awomoyi AA, et al. The toll-like receptor 4 Asp299Gly variant: no influence on LPS responsiveness or susceptibility to pulmonary tuberculosis in The Gambia. Tuberculosis (Edinb). 2004; 84: 347-52.

12. Davila S, Hibberd ML, Hari Dass R, et al. Genetic association and expression studies indicate a role of toll-like receptor 8 in pulmonary tuberculosis. PLoS Genet. 2008; 4: e1000218.

13. Schroder NW, Schumann RR. Single nucleotide polymorphisms of Toll-like receptors and susceptibility to infectious disease. Lancet Infect Dis. 2005; 5: 156-64.

14. Thuong NT, Hawn TR, Thwaites GE, et al. A polymorphism in human TLR2 is associated with increased susceptibility to tuberculous meningitis. Genes Immun. 2007; 8: 422-8.

15. Zhang YX, Xue Y, Liu JY, et al. Association of TIRAP (MAL) gene polymorhisms with susceptibility to tuberculosis in a Chinese population. Genet Mol Res. 2011; 10: 7-15.

16. Xue $Y, Z$ hao $Z Q$, Hong $D$, et al. Lack of association between $M D-2$ promoter gene variants and tuberculosis. Genet Mol Res. 2010; 9: 1584-90.

17. Xue $Y, Z$ hao ZQ, Wang HJ, et al. Toll-like receptors 2 and 4 gene polymorphisms in a southeastern Chinese population with tuberculosis. Int J Immunogenet. 2010; 37: 135-8.

18. Ogus AC, Yoldas B, Ozdemir $\mathrm{T}$, et al. The Arg753GLn polymorphism of the human toll-like receptor 2 gene in tuberculosis disease. Eur Respir J. 2004; 23: 219-23.

19. Proell M, Riedl SJ, Fritz JH, et al. The Nod-like receptor (NLR) family: a tale of similarities and differences. PLoS One. 2008; 3 : e2119. 
20. Austin CM, Ma X, Graviss EA. Common nonsynonymous polymorphisms in the NOD2 gene are associated with resistance or susceptibility to tuberculosis disease in African Americans. J Infect Dis. 2008; 197: 1713-6.

21. Torrelles JB, Azad AK, Schlesinger LS. Fine discrimination in the recognition of individual species of phosphatidyl-myo-inositol mannosides from Mycobacterium tuberculosis by C-type lectin pattern recognition receptors. J Immunol. 2006; 177: 1805-16.

22. East L, Isacke CM. The mannose receptor family. Biochim Biophys Acta. 2002; 1572: 364-86.

23. McGreal EP, Miller JL, Gordon S. Ligand recognition by antigen-presenting cell C-type lectin receptors. Curr Opin Immunol. 2005; 17: 18-24.

24. Beharka AA, Crowther JE, McCormack FX, et al. Pulmonary surfactant protein A activates a phosphatidylinositol 3-kinase/calcium signal transduction pathway in human macrophages: participation in the up-regulation of mannose receptor activity. J Immunol. 2005; 175: 2227-36.

25. Schlesinger LS, Kaufman TM, Iyer $S$, et al. Differences in mannose receptor-mediated uptake of lipoarabinomannan from virulent and attenuated strains of Mycobacterium tuberculosis by human macrophages. J Immunol. 1996; 157: 4568-75.

26. Kang PB, Azad AK, Torrelles JB, et al. The human macrophage mannose receptor directs Mycobacterium tuberculosis lipoarabinomannan-mediated phagosome biogenesis. J Exp Med. 2005; 202: 987-99.

27. Schlesinger LS. Macrophage phagocytosis of virulent but not attenuated strains of Mycobacterium tuberculosis is mediated by mannose receptors in addition to complement receptors. J Immunol. 1993; 150: 2920-30.

28. Nigou J, Zelle-Rieser C, Gilleron M, et al. Mannosylated lipoarabinomannans inhibit $I L-12$ production by human dendritic cells: evidence for a negative signal delivered through the mannose receptor. J Immunol. 2001; 166: 7477-85.

29. Alter A, de Leseleuc L, Van Thuc N, et al. Genetic and functional analysis of common MRC1 exon 7 polymorphisms in leprosy susceptibility. Hum Genet. 2010; 127: 337-48.

30. Hattori T, Konno S, Hizawa N, et al. Genetic variants in the mannose receptor gene (MRC1) are associated with asthma in two independent populations. Immunogenetics. 2009; 61: 731-8.

31. Hattori T, Konno S, Takahashi A, et al. Genetic variants in mannose receptor gene $(M R C 1)$ confer susceptibility to increased risk of sarcoidosis. BMC Med Genet. 2010; 11: 151.

32. [Internet] Ministry of Health of China. Diagnostic criteria for pulmonary tuberculosis. http://www.moh.gov.cn/ publicfiles/business/cmsresources/zwgkzt/cmsrsdocument/ doc3242.pdf.

33. Liu $\mathrm{CP}, \mathrm{Li} X \mathrm{XG}$, Lou JT, et al. Association analysis of the $P H O X 2 B$ gene with Hirschsprung disease in the Han Chinese population of Southeastern China. J Pediatr Surg. 2009; 44: 1805-11. 